\title{
Los migrantes retornados a la Región Tejupilco, Estado de México
}

\author{
Renato Salas Alfaro*
}

Recepción: 26 de enero de 2016

Aceptación: 4 de mayo de 2016

*Universidad Autónoma del Estado de México, México. Correo electrónico: rnt13@hotmail.com Se agradecen los comentarios de los árbitros de la revista.

(cc) $\$$

\author{
Resumen. Se analizan las habilidades producti- \\ vas que los migrantes retornados del extranjero \\ traen consigo, la forma en que las aplican y las \\ limitaciones que enfrentan en sus lugares de \\ residencia. Con tal fin, se realizaron 40 entre- \\ vistas a profundidad con migrantes retornados \\ hacia la Región Tejupilco. Los resultados exhi- \\ ben que ellos enfrentan diversas restricciones: \\ carencias de recursos, falta de empleos, bajos \\ salarios, corrupción, tráfico de influencias, \\ distribución inequitativa de apoyos, eventos \\ que les restringen aplicar sus conocimientos \\ laborales y otras habilidades personales, que en \\ contraste mantienen ociosos o subempleados \\ a alrededor de $90 \%$ de los entrevistados. \\ Palabras clave: migrantes, políticas públicas, \\ habilidades productivas, Estado de México, \\ modos de vida.
}

The Returning Migrants to the Region of Tejupilco in the State of Mexico

Abstract. This paper analyzes the productive skills that the abroad returning migrants bring with them, how they apply them and the constraints they face in their homes. To this end, forty-depth interviews were done to migrants returned to the Tejupilco region. The results display that they face various constraints: lack of resources, lack of jobs, low wages, corruption, influence peddling, inequitable distribution of support, events that restrict them to apply their labor skills and other personal skills; in contrast, around ninety percent of the respondents remain idle or underemployed.

Keywords: migrants, public policies, productive skills, State of Mexico, lifestyle.

\section{Introducción}

Cuando una persona migra de su lugar de origen o retorna, ya sea forzada o voluntariamente, es porque se ve influida por diversas circunstancias: necesidad económica, hastío, nuevos planes, diversos miedos y violencias. $\mathrm{Al}$ moverse de residencia lleva consigo sueños, expectativas, vicios, conocimientos, habilidades, preocupaciones y otros rasgos que se adquieren durante el trasiego. Las distintas formas de convivencia, de trabajo, hábitos y costumbres que afrontan los obligan a desplegar diversas capacidades. En este sentido, sus aprendizajes sociales, académicos y laborales que poseen les permiten acomodarse a nuevas condiciones. El caso de la migración internacional abarca la gestión de la idea de migrar, la negociación de metas personales y familiares que se buscan obtener, el financiamiento, los peligros del traslado y cruce de la frontera, la llegada e instalación en el otro país o la ubicación laboral. El retorno por su parte incluye inseguridad laboral en sus lugares de origen, carencias económicas y ambientes políticos no favorables a las ideas y actitudes de emprendimiento o deficiencias en servicios públicos que pueden limitarlos en la construcción de sus modos de vida. $\mathrm{Al}$ respecto, es posible que el sujeto que retorna a la entidad mexiquense traiga consigo habilidades y conocimientos que pueda emplear productivamente. También es probable que no traiga nada útil, que retorne con vicios o que sus conocimientos y activos acumulados sean de mala calidad. Es probable que aun trayendo activos, conocimientos y diversas capacidades productivas, el entorno de sus lugares de origen no le permita emplearlos a plenitud y vivir de ellos.

De este modo, identificar las habilidades técnicas y sociopersonales que traen los migrantes, la forma en que las utiliza 
en la Región Tejupilco y delinear algunas propuestas para potenciar su aplicación productiva constituyen el núcleo de esta investigación. Para ello, se entrevistaron a profundidad a 40 migrantes retornados del extranjero hacia localidades de la región. Cada uno fue localizado mediante el procedimiento de bola de nieve y redes de contactos familiares. El trabajo de campo se llevó a cabo entre diciembre de 2012 y enero de 2013. La guía de entrevista incluyó aspectos sociodemográficos (edad, escolaridad, estado civil), situación emocional, económica y productiva antes de migrar, la vivencia migratoria (formas, lugares de cruce, costos, peligros), la adquisición de conocimientos laborales (empleos, capacitaciones), el proceso de reinserción al retorno, así como sus propuestas para construir mejores modos de vida.

\section{Migración de retorno y habilidades}

La migración favorece el tránsito de las personas entre diversos lugares, condiciones de vida (laborales y culturales), lo cual puede favorecer el desarrollo de algunos componentes que forman sus capacidades productivas y de sus hogares (humano, financiero, técnico, social) y determinan el tipo de vida que pueden lograr. Un modo de vida incluye las capacidades materiales y sociales del hogar que se desagregan bajo cinco formas de capital (social, humano, físico, financiero y natural), así como las actividades que pueden realizar y la forma en que acceden a ellas. Todo lo anterior enmarcado por las relaciones sociales e institucionales en el contexto de referencia (figura 1).

A saber, las personas tienen un modo de vida que puede ser frágil o estable según sus capacidades, ya que las acciones que despliegan para vivir en sus hogares dependen de la cantidad, calidad y empleabilidad de sus activos. Quienes carecen de activos poseen de mala calidad o no pueden emplearlos, sólo alcanzan a construir modos de vida vulnerables y supeditados al vaivén de la economía, las políticas, circunstancias naturales (clima, desastres) e intereses de actores poderosos. No obstante, cuando un hogar logra poseer capacidades productivas en cantidad, calidad y aplicabilidad que le permiten hacer frente a las crisis económicas, saltar sus restricciones y al mismo tiempo mejorar sus capacidades, se dice que lograron un modo de vida sostenible (Chambers y Conway, 1992; Banco Mundial, 2001).

Así, la migración puede jugar un papel importante en la consecución de distintos activos por diversas vías: remesas, activos de bienestar (casas, muebles, autos) y productivos (negocios, tierras), conocimientos laborales, actitudes y nuevas mentalidades. Por ejemplo, el hogar puede destinar remesas para mejorar la alimentación, educación y salud. En el caso del capital humano, al cooperar en las actividades de la iglesia, fiestas de la localidad, compadrazgos y demás, favorece su capital social. Asimismo, los migrantes cooperan en el capital social al desarrollar capacidades para entablar relaciones sociales con desconocidos que se trasladan y cruzan la frontera con ellos o con otras personas que los apoyan para buscar empleo, alojamiento y convivencia. El capital físico refiere la posesión de herramientas, técnicas y procesos de producción; los migrantes cuando tienen empleo están en contacto con nuevas formas de trabajo, horarios, procesos, herramientas, hábitos y demás. Los otros capitales tienen que ver con el manejo equilibrado de sus recursos naturales (bosques, ríos), con hábitos de ahorro y acumulación que desarrollan hogares e individuos. La contrariedad es que dicha práctica laboral implica riesgos tanto en la seguridad del migrante como en la sostenibilidad de los hogares que dependen de él. Los migrantes pueden ser heridos, encarcelados, formar otra familia, puede ocurrir separación familiar, que no haya envío de remesas, adquieran vicios, que no vuelvan o que mueran. No obstante, los migrantes laborales asumen estos riesgos con la idea de obtener un mejor modo de vida y

\section{Figura 1. El modo de vida.}

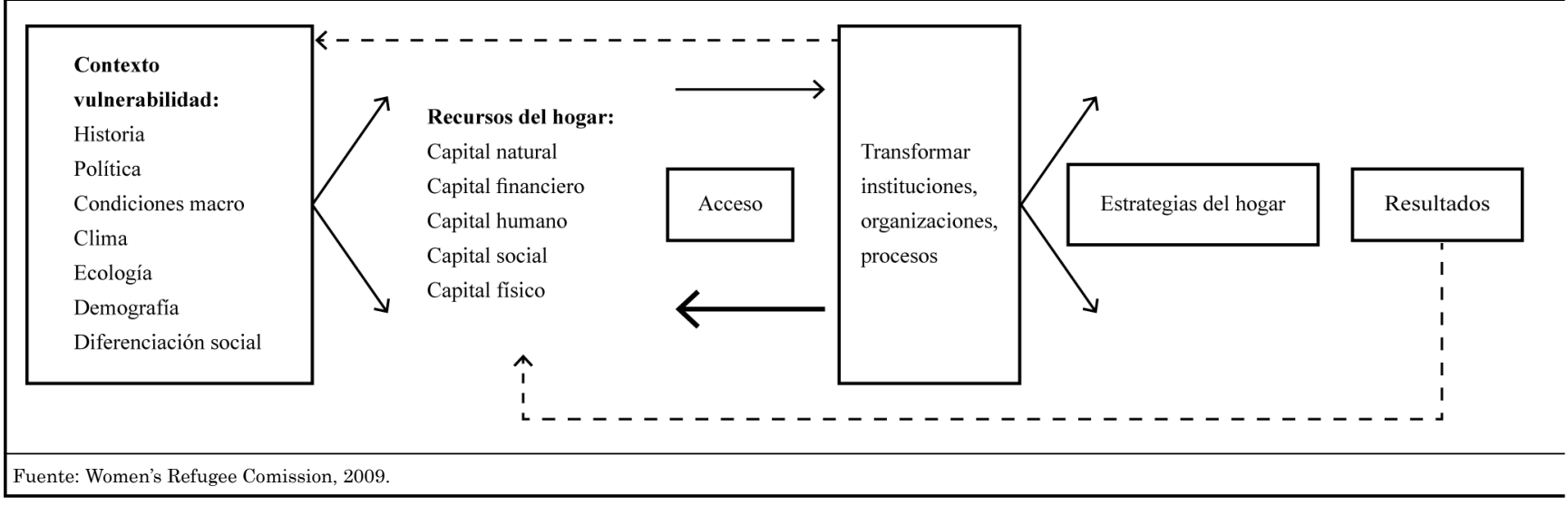


transforman estas adversidades en una fuente de habilidades. De hecho, podría decirse que a sabiendas de las condiciones adversas, al aceptarlas, tanto hogares como migrantes comparten un cierto heroísmo épico (Carretero, 2012).

Algunas investigaciones han detectado que los hogares en México tienen distintos activos y de diversa calidad. Cuando tienen fuerza de trabajo y no pueden emplearla en su localidad voltean hacia mercados laborales externos, lo cual hace que cada vez sea más aceptado emprender la marcha al extranjero buscando conseguir mejores modos de vida (Reyes y Gijón, 2007; Stark, 1982). Con todo y adversidades, este proceso puede contribuir a mejorar las capacidades de las personas y hogares. En el caso de los mexiquenses, antes de que ocurra la migración, la mayoría de ellos posee conocimientos laborales, cuentan con capacidades para aprender y tienen una escolaridad promedio de secundaria terminada. Como señalan algunos investigadores, las capacidades y conocimientos previos, al entrar en contacto con otras experiencias, forman otras habilidades. Cuando las personas enfrentan nuevos desafíos y generan estrategias para superarlos, se amplían sus habilidades previas; al principio el sujeto se desequilibra, pero buscará acomodarse al nuevo esquema y tener un equilibrio superior (Monereo et al., 1999; Ausubel, 1976; Piaget, 1978).

Es decir, los migrantes llevan consigo objetivos de trabajo que sería enviar dinero a casa por ejemplo. Esta vía le permite adquirir conocimientos y ampliar sus capacidades. Sin embargo, también surgen los problemas que enfrentan al tener que buscar empleo, comunicarse en otro idioma, superar el racismo, ahorrar y enviar remesas, lo cual puede forzar o motivar a que ellos desarrollen habilidades que les permitan vivir en el nuevo entorno. La evidencia de que esto ocurre se aprecia en diversos estudios (Sabatés, 2007; Chávez, 1995; Salas, 2010). Otras investigaciones han encontrado que los migrantes retornan cuando cumplen sus objetivos. $\mathrm{Al}$ retorno invierten en actividades productivas o emprenden negocios (Lucas y Stark, 1985; Dustmann, 2001). No obstante, en general las evidencias encontradas en México, Jamaica, Sri Lanka y otros países exhiben que los migrantes retornados enfrentan una reinserción social y productiva difícil, a pesar de contar con conocimiento laboral, capital, habilidades personales e intenciones de quedarse. Los entornos suelen ser hostiles para los retornados porque requieren apoyos para completar las actividades que quieren realizar (créditos, cursos de formación empresarial, administración de pequeños negocios, finanzas personales, empleos) (Sabatés, 2007; Papail, 2003; Thomas Hope, 1999; Athukorala, 1990; Dustmann, 2001; Piracha y Vadean, 2009; Borodak y Piracha, 2010; Espinosa, 1998).

\section{La Región Tejupilco}

La Región Tejupilco se integra por los municipios de Amatepec, Luvianos, Tejupilco y Tlatlaya. Se localiza al suroeste del Estado de México, enclavada en la Sierra Madre del Sur. Posee un relieve de montañas, cerros y cañadas dentro de las sierras Nanchititla, La Goleta y San Vicente. Colinda con los estados de Michoacán y Guerrero. Es una región hídrica importante en extensión y volumen de corrientes superficiales porque aquí se encuentra la depresión del Balsas, así como las cuencas río Cutzamala y río Balsas-Zirándaro.

Es una región rural con altos niveles de pobreza, aunque en general dos terceras partes de la población económicamente activa (PEA) realizan actividades no agrícolas. Sólo en Luvianos y Tlatlaya más de $40 \%$ de la PEA vive de estas actividades. Hasta 2010 registra una población total de 158 189 habitantes: Luvianos cuenta con 27 781, Amatepec 26 334, Tlatlaya 32997 y Tejupilco 71 077. Entre 1990 y 2000 la región había incrementado su población en $18 \%$, pero entre 2000 y 2010 , se redujo en casi $2 \%$. De acuerdo con las cifras del Consejo Nacional de Evaluación (Coneval) hasta 2010 , en promedio $57 \%$ de la población regional sufre alguna situación de pobreza; en este caso, destacan Luvianos y Tlatlaya porque están ubicados por porcentaje entre los diez municipios porcentualmente más pobres en la entidad. El primero tiene casi $82 \%$ de su población en esta condición y el segundo 74\%; Amatepec y Tejupilco tienen cifras menores: 67 y $70 \%$ respectivamente.

La región posee una infraestructura formada de caminos rurales entre sus localidades; se conecta con Toluca y el estado de Guerrero mediante la carretera Toluca-Ciudad Altamirano, la cual permite a la población establecer intercambios comerciales en ambas partes. Cuenta con nueve planteles de bachilleres, cuatro Escuelas Normales, un Hospital General en Tlatlaya y 78 Centros de Salud en los demás municipios, tanto del Sector Salud (SSA), como del Instituto Mexicano del Seguro Social (IMSs), dos terminales de autobuses (Tejupilco y Tlatlaya), seis comandancias de policía. Luvianos y Tejupilco fungen como principales centros regionales de comercio, donde se abastecen otras localidades.

\section{La migración de retorno en la Región Tejupilco}

El análisis se realizó a partir de 40 entrevistas hechas a profundidad a migrantes de retorno en esta región. A partir de la voz del actor puede afirmarse que la migración hacia los Estados Unidos de América comenzó a finales de 1940; hombres adultos, preferentemente jefes de familia con experiencia laboral agrícola iniciaron este andar. Aunque el 
inicio fue irregular, desde los noventa, la migración adquirió alta importancia, se formaron redes sociales que apoyaban el traslado, se incorporaron mujeres y menores de edad, la experiencia laboral y escolaridad en general fue más diversa y de mejor calidad. Por ejemplo, $40 \%$ de los entrevistados desde antes de migrar tenía padre o madre con experiencia migratoria internacional, además $90 \%$ tenía otros parientes en la misma condición.

En general, casi dos tercios (63.3\%) de los migrantes retornados son hombres, el resto mujeres. En la región el predominio masculino en la migración internacional es evidente, similar a lo que ocurre en toda la entidad, pero aquí se aprecia mayor incorporación de mujeres que en otras regiones, donde rondan apenas 15\% (Salas, 2011). Los migrantes partieron de la región después de la década de los noventa $(90 \%)$. Son jóvenes que realizaron sus primeros viajes al extranjero con 25.6 años de edad promedio, aunque $40 \%$ migró antes de los 20 años. Partieron con escolaridad promedio de 8.5 grados, $10 \%$ no tenía escolaridad y $16 \%$ poseía un grado universitario. Sus lugares de destino fueron cambiando conforme aumentaba su experiencia migrante y sabían de nuevos lugares con empleos. En las primeras migraciones arribaron en orden de importancia a Houston, Austin, Texas, condados de Chicago, Santa Ana, San Diego, Los Ángeles, condados de Carolina del Norte y Carolina del Sur. También llegaron a lugares de Wisconsin y Tennessee y luego con la experiencia agregaron destinos como Phoenix, Florida y Atlanta y otros más.

El retorno definitivo a la región ocurrió entre 2001 y 2012. En este periodo retornaron aproximadamente tres de cada cuatro $(73.3 \%)$. Nadie retornó por una sola causa, aunque la intención de ver a la familia prevalece como una causal básica en siete de cada diez retornados. Los demás esgrimen entre sus razones: tener objetivos cumplidos, escasez de trabajo y reducción del ingreso, enfermedades o muerte de familiares, hastío de ser indocumentado, de estar escondiéndose y problemas familiares o con la justicia. No obstante, se observa una mezcla de razones para retornar a la región. Por ejemplo, de quienes querían ver a la familia, 30\% también menciona que retornó porque tenía aburrimiento y soledad en el extranjero, otro $20 \%$ prefirió traer sus hijos para criarlos en México, otro $30 \%$ señala que ya estaba cansado de estar lejos y enfadado de ser indocumentado. El resto menciona otras causales asociadas a su retorno, aunque la idea de reunirse con la familia fue la detonante.

En promedio registran un periodo efectivo de estancia en el extranjero de 7.2 años (7.9 hombres y 5.9 mujeres), esto es, descontando el tiempo que pasaban en México durante sus retornos intermedios. La mayor permanencia masculina es una constante en localidades de menor tradición migratoria porque los hombres migran primero por razones que tienen que ver con proveer a sus familiares, por el rol masculino o asunción de riesgos; después lo hacen las mujeres con y sin ayuda de aquellos. Asimismo, el retorno definitivo es relativo. Las evidencias referidas muestran que la posibilidad de regresar al extranjero es latente entre los migrantes. Si las condiciones socioeconómicas que presentan sus entornos y otras circunstancias familiares no son adecuadas, terminan por regresar a Estados Unidos.

\section{1. Habilidades adquiridas o depuradas en la mi- gración internacional}

Todos los retornados de esta región antes de migrar tenían empleo; $60 \%$ trabajaba hasta en dos actividades distintas, poseía experiencia laboral y manejaba oficios y profesiones, además se dedicaba a labores agrícolas, construcción y otros oficios, algunos también estudiaban. Vale la pena resaltar que si bien en la región había actividades separadas para hombres y para mujeres, en Estados Unidos, ambos se involucraron en actividades sin distinción de género (agrícolas, domésticas o de limpieza y cocina), aunque las mujeres no realizaron oficios de construcción.

Las mujeres en su caso desempeñaban tareas de limpieza en casas y establecimientos, algunas eran recepcionistas.

Las habilidades laborales adquiridas por los migrantes de la región se muestran en el cuadro 1 . Se advierte correlación entre tareas que realizaban en la región y las del extranjero. Por ejemplo, la mayoría de quienes sabían labores agrícolas en México, en el extranjero se ubicaron en actividades similares; el resto trabajó en restaurantes, operador de maquinaria, herrería, construcción, jardinero y ayudante general. Quienes se dedicaban a la limpieza, en el extranjero un porcentaje similar desempeñó lo mismo y otros laboraron en restaurantes, el campo y la costura.

Quienes antes de migrar se dedicaban a las ventas o al comercio, en el extranjero se emplearon en actividades del campo, construcción, restaurantes, limpieza y jardineros. Los de construcción, se dedicaron a lo mismo, otros al campo o trabajar en restaurantes, en fábricas de pinturas y en almacenes. En general los oficios que desempeñaban en México, también fungieron como su principal actividad en Estados Unidos, aunque bajo otras normas, lo cual sugiere la importancia de contar con capacidades previas. Asimismo, otros migrantes desempeñaron oficios nuevos de mayor y menor calificación: el oficio de cocinero lo ejerció casi un tercio, eso implica calificación laboral, entrenamiento, capacitación, dominio de idioma y saber de procesos productivos y administrativos. Para llegar a ese puesto primero laboraron en otros de menor rango y eso refleja ascensos laborales en entornos de amplia dificultad. 
Aunque dos tercios de los migrantes no obtuvieron ningún ascenso laboral en el extranjero (67.5\%), los demás sí ascendieron en áreas de cocina de restaurantes (22.5\%), construcción (7.5\%), fábricas (2.5\%). El área de cocina ilustra el aprendizaje laboral. Los migrantes iniciaban en la limpieza, luego de meseros, asistentes de cocina, cocineros, chefs y encargados del restaurante. En la construcción y las fábricas, fue similar: comenzar en un puesto de baja calificación como ayudante general, aprender inglés con el tiempo y comenzar con un proceso productivo para asumir responsabilidad en puestos de mayor calificación laboral y salario.

El conocimiento laboral que aprendieron en Estados Unidos y que trajeron consigo se muestra en el cuadro 2, aunque resulta difícil establecer porcentajes para cada conocimiento porque los migrantes traen más de uno, en este caso se toma en consideración aquel conocimiento laboral de mayor valor agregado. Puede notarse que casi la mitad de los migrantes trajo conocimiento laboral básico y los demás traen conocimiento de mayor valor agregado. Preparar comidas y dirigir la cocina de un restaurante son los principales conocimientos laborales calificados que traen al retorno a $20 \%$ de los migrantes. $\mathrm{Al}$ sumar a los ayudantes de cocina que realizaban tareas calificadas (5\%), los conocimientos calificados en el área de restaurante reúnen una cuarta parte. El resto de conocimientos incluye una amplia variedad de actividades que los retornados pueden hacer en la región: labores de construcción especializada como el roofing y operar maquinaria pesada, entre otras que suman casi otro $20 \%$, además de la soldadura, uno más que es profesionista y otro que sabe instalar malla ciclónica.

Además de los conocimientos laborales, los migrantes reconocen otros beneficios personales derivados de su migración al extranjero: $83.3 \%$ valora que con ella mejoraron su educación y maduraron en lo personal, así como en el aspecto familiar. De este grupo, la mitad (53.3\%) menciona que tiene más consciencia de lo que ocurre a su alrededor y de lo que hace. En este aspecto, otro tercio $(36.6 \%)$ piensa que es más responsable, pues considera que su experiencia laboral y social que tuvo al desarrollar habilidades para comunicarse y enfrentar obstáculos lo hicieron valorar sus acciones. Algunos mencionan que la experiencia migratoria ayudó a reforzar su unión familiar. En otros casos resalta más la obtención de una casa propia, un patrimonio (ahorros, animales, pequeñas inversiones), aprender inglés, ganar autoestima e independencia personal y vencer la timidez. En voz de sus actores:

\begin{tabular}{|c|c|}
\hline Previo a la migración & Porcentaje \\
\hline Campo (sembrar, cosechar, entre otros) & $26.6 \%$ \\
\hline Limpieza (en casas o establecimientos) & $23.3 \%$ \\
\hline Ventas/comercio & $16.6 \%$ \\
\hline Construcción & $13.3 \%$ \\
\hline Ayudante general & $13.3 \%$ \\
\hline Operador de maquinaria & $10.0 \%$ \\
\hline Recepcionista/secretaria & $10.0 \%$ \\
\hline Docente & $10.0 \%$ \\
\hline Jardinero & $10.0 \%$ \\
\hline Chofer & $10.0 \%$ \\
\hline Hojalatero/mecánico & $6.6 \%$ \\
\hline Mesero & $6.6 \%$ \\
\hline $\begin{array}{l}\text { Otros (chef, almacenista, estilista, velador, bolero refores- } \\
\text { tador, cibercafé, policía, plomero, perforista en mina, CFE, } \\
\text { cobrador de la línea de transporte fecha roja) }\end{array}$ & $40.0 \%$ \\
\hline En Estados Unidos & Porcentaje \\
\hline Construcción (poner pisos, teja, carpintería, instalaciones) & $23.3 \%$ \\
\hline Limpieza de casas o establecimientos y cuidar niños & $23.3 \%$ \\
\hline Lavaplatos & $20.0 \%$ \\
\hline Cocina & $36.6 \%$ \\
\hline Mesero & $16.6 \%$ \\
\hline Almacenes y conteos & $16.6 \%$ \\
\hline Podar árboles, pasto & $16.6 \%$ \\
\hline Campo & $13.3 \%$ \\
\hline Hablar inglés & $10.0 \%$ \\
\hline Pintar & $10.0 \%$ \\
\hline Soldadura, herrería & $6.6 \%$ \\
\hline Manipular maquinaria pesada & $6.6 \%$ \\
\hline Obrero & $6.6 \%$ \\
\hline Manejar camionetas grandes & $6.6 \%$ \\
\hline $\begin{array}{l}\text { Otros (hacer mallas ciclónicas, armar celulares, fabricar } \\
\text { tubo galvanizado, elaborar piezas de yeso, recamarera, } \\
\text { coser almohadas y calcetines, cajera, mánager de cocina, } \\
\text { lavar tambos) }\end{array}$ & $33.3 \%$ \\
\hline \multicolumn{2}{|c|}{$\begin{array}{l}\text { Nota: *los porcentajes no suman } 100 \% \text { porque algunos migrantes realizan más de } \\
\text { una actividad. } \\
\text { Fuente: elaboración propia. }\end{array}$} \\
\hline
\end{tabular}

Conocimiento práctico aprendido en Estados Unidos.

\begin{tabular}{lr} 
Conocimiento y tipo & Porcentaje \\
\hline Conocimiento básico general & 45.0 \\
Cocinero (restaurante, comida rápida) & 20.0 \\
Ayudante de cocina & 5.0 \\
Chofer, camión pesado, montacargas, volteo, grúas & 2.5 \\
Construcción, plomería, roofing, pisos, carpintería & 15.0 \\
Profesionista & 2.5 \\
Soldadura industrial & 5.0 \\
Tapicería & 2.5 \\
Poner malla ciclónica & 2.5 \\
\hline Fuente: elaboración propia. & \\
\hline
\end{tabular}


Yo me he hecho más maduro en todos los sentidos [...]. Ahora le ayudo a mi esposa en todo lo que puedo en las labores del hogar y trato de ser mejor persona (Abel A. entrevistado en Tejupilco).

Pues estamos unidos. La economía de mi familia ya está más contenta porque tienen más cositas [...]. [La migración] sí me hizo ver de otra manera las cosas: ser una personas más abierta, hacer mejor las cosas, echarle ganas, porque la vida es muy diferente allá que aquí (Ariadna S. H., entrevistada en Tlatlaya).

Creo que sí piensa uno mejor, tiene más pensamientos uno porque allá la gente es más buena gente y piensa uno mejor allá que aquí, porque aquí no piensa uno nada. Allá me ayudaron personas a cambiar el pensamiento más que nada, a portarse uno mejor, a pensar mejor, porque yo cuando iba de aquí para allá pues no iba bien portada, iba menos educada (Oralia L., entrevistada en Tejupilco).

\section{2. Las actividades como retornados}

A su retorno, casi $87 \%$ de los migrantes realiza una o más actividades productivas para vivir. Una de las que destaca es la atención de los negocios propios que establecieron y financiaron con remesas: carnicería, miscelánea, tortillería, taquería, sastrería y otros; 40\% aplica sus aprendizajes laborales, actitudes y cambios personales. Entre quienes no lograron poner un negocio el deseo de hacerlo permanece latente. Por ejemplo: "pus ahorita no tengo nada pero si me gustaría poner una cocina económica" (Juan Carlos G., entrevistado en Tejupilco). El resto se dedica a otras actividades: $13.3 \%$ trabaja en casas de empeño y actividades relacionadas, $16.6 \%$ se dedica al campo, $16.6 \%$ atiende negocios no propios, $10 \%$ ha trabajado en la junta local de caminos y otros empleos, dos migrantes más imparten clases de inglés en escuelas y uno más se dedica a estudiar.

Es necesario enfatizar que en la Región Tejupilco un tercio de los migrantes retornados no utiliza en forma productiva ninguno de los conocimientos laborales que trajeron del extranjero (35\%); 55\% aplica al menos algo de lo que saben hacer y solamente $10 \%$ de los migrantes emplea todo su conocimiento laboral y puede vivir de eso. En general, las áreas donde más aplican sus conocimientos se ubican en construcción, restaurantes, actividades agrícolas y personales; incluyen labores de trabajo en equipo, impulsar hábitos de limpieza, honestidad, responsabilidad y madurez, conocimientos agrícolas, construcción y herrería y donde sea necesario hablar inglés.

Los migrantes retornados señalan que no han tenido oportunidad, ni han encontrado la forma de aplicar sus conocimientos laborales, ideas de emprendimiento, concretar proyectos privados y sociales en forma productiva, ya que los emplean para uso propio en sus hogares (arreglar sus autos, casas, preparar comidas familiares). Las razones son variadas y no existe una causal única o determinante que los restrinja. Al contrario, casi la mitad (46.6\%) señala que la economía deprimida del país y la falta de financiamiento son los principales factores que los limitan. Uno de cada cinco alude a la falta de estudios y certificados formales (20\%), falta de empleo $(13.3 \%)$, algunos no quieren hacer lo mismo que en el extranjero $(20 \%)$, el resto tiene desilusión y se dedica a otras actividades. También se menciona que la corrupción y compadrazgo, frecuente en instituciones públicas y privadas, así como los trámites y papeleo, pero en particular la violencia que aqueja esta región, afecta y frena iniciativas de emprendimientos en pequeños negocios.

Los testimonios permiten hacerlo más evidente:

Aquí el impedimento es que hay gente que te pide estudios y sí los tienes, pero hay gente que no los tiene y desgraciadamente sólo se arregla con palancas. Si llegas de Estados Unidos y conoces a alguien en la presidencia, de volada te acomoda, y si no pues a buscarle por otro lado. Desgraciadamente aquí rige mucho tener palanca. Si tengo palancas, puedo trabajar. Con calma se pueden aplicar pues cosas que aprendiste allá: trabajar en equipo, pensar las cosas antes de hacerlas, ser limpio en tu trabajo, ser honesto, no tratar de, bueno, como dice un dicho mexicano, "no fregar al prójimo", no robar, ni nada de eso. En eso me ha ayudado lo que viví en el norte (Abel A., entrevistado en Tejupilco).

Aquí sí pues, hay oportunidades, pero lamentablemente a veces no cumplen con las expectativas que queremos: nos gusta el dinero rápido y fácil y ganar bien. Cuando vas a un empleo lo primero que preguntas es cuánto voy a ganar. Mejor dicho, la pregunta sería ¿qué sabes hacer? México es una economía fuerte, así que es cuestión de buscar las oportunidades y de trabajar. Allá lo más que te ayuda, todo lo malo que vives, es el adquirir la capacidad de sobresalir sobre los mejores. Allá si no eres hábil o listo, no puedes sobresalir, tienes que adquirir habilidad y destreza en lo que hagas con una mentalidad positiva, la comunicación con las personas, el socializar y trabajar en equipo. Ser sociable te abre muchas oportunidades (Homero M., entrevistado en Luvianos).

Desde que regresé, trabajo en el área de cocina del Issemyn [sic], entonces creo que sí sirve lo aprendido, pero también porque la migración me ayudó a saber meterme, saber buscar, saber hablar, perder la pena de pedir trabajo (Gabriel S., entrevistado en Luvianos). 
Algo que afecta las actividades de los migrantes e iniciativas de emprendimiento es la inseguridad que vive la región:

La soldadura, con mi hermano hemos hecho varios trabajos de soldadura, techos. Los podemos hacer, darle forma, ya que el de lámina está así, sí, la forma que uno pues, lamina, monta, que sea tubular, cuadrado, pijas. Pero puse pues una tortillería, pero por la situación de que hay aquí en el país, cómo se le puede llamar, la situación de los cárteles, me levantaron por envidia. Yo tenía bastante trabajo. Me levantó uno de los grupos delictivos, me dio miedo y tuve que vender mi máquina. Como me espanté me fui a Cuernavaca, Toluca y Acapulco con mi familia. Me entró un pánico, temor, me daba miedo salir a la puerta de la casa. Después de un año me vine. Mi hijo el mayor arregló el problema y me dieron chance de regresar aquí y me puse un negocito de bolsas y copiadoras y aquí estamos trabajando (Sandino B., entrevistado en Tlatlaya).

No obstante las limitaciones, casi $85 \%$ de los migrantes quiere emprender labores agrícolas, ganaderas, negocios diversos (comida, tiendas, purificadoras de agua, panaderías), participar en su localidad (infraestructura comunal, calles, luz, proteger el medioambiente, ayudar a los discapacitados y a las mujeres maltratadas, fomentar el arte, la cultura y el deporte). Estas son algunas de sus aspiraciones:

En los proyectos de campo me gustaría sembrar maíz o que nos dieran un dinero para una ternera, unos animales (Ernesto R., entrevistado en Tlatlaya).

Pues a mí me gustaría participar en actividades que tengan que ver con el medioambiente, actividades de concientización para el cuidado del agua, para el cuidado de las aéreas verdes, para no tirar mucha basura en el agua y todo eso (Graciela S., entrevistada en Tejupilco).

Pues ora sí que me gustaría fomentar, bueno a mí, me gusta mucho lo que es el arte, música, fotografía, pintura, dibujo, fomentar formas de cultura, de baile, cursos deportivos. Si se diera la oportunidad, me gustaría ser maestro de esto (Víctor N., entrevistado en Tlatlaya).

Los migrantes retornados también aportan opiniones desde su perspectiva y experiencias sobre lo que podría hacerse en la región para ampliar el campo de acción y aplicar sus conocimientos laborales. Los aportes se muestran en el cuadro 3. La clasificación porcentual es por estrategia y no todos alcanzan a formular alguna medida concreta. Algunas propuestas están centradas en la acción del agente externo que puede solucionar algo, pero otras mencionan la urgencia de participar cada ciudadano en la construcción de sus condiciones de vida. Por ejemplo, puede verse en orden de importancia que casi $75 \%$ de los migrantes considera que deben generarse más empleos, un tercio piensa que el gobierno debe mejorar sus prácticas y preocuparse más por el pueblo y $20 \%$ postula que el gobierno debe reducir la corrupción. De este modo, se señalan las cosas que funcionan mal.

En este ánimo de mejorías, destaca una serie de recomendaciones y reclamos para cambiar de mentalidad, ser más activos, más arriesgados, exigir más apoyo a las pequeñas iniciativas, apoyos al campo, entre otros, como en seguida lo expresan:

Es muy difícil porque no todos piensan igual. Tanto políticos como nosotros, todos tenemos culpa, pero tal vez sería importante implementar el empleo, para que los jóvenes en vez de algo malo busquen un trabajo. De esa manera combatir la delincuencia. Más turismo, más economía, más no sé. Las empresas que hay están saturadas de solicitantes. Fomentar los empleos en todo el país; la gente va a preferir trabajar que hacer algo ilícito (Elmer G., entrevistado en Tejupilco).

Primeramente que todo sea equitativo, porque si vamos hablar de dinero, se lo llevan los que están arriba. Hay mucha injusticia social. Yo siempre he estado en desacuerdo en este sistema de gobierno porque el beneficio es siempre personal y para los

\begin{tabular}{ll}
\hline Cuadro 3. Propuestas de los migrantes para el desarrollo de la región. \\
\hline Estrategias & Porcentaje de migrantes \\
\hline Generar/crear más empleos & 73.3 \\
Gobierno comprometido con el pueblo & 36.6 \\
Eliminar/reducir la corrupción & 20.0 \\
Más y mejor seguridad & 16.6 \\
Ciudadanos comprometidos & 13.3 \\
Más apoyo a la educación & 13.3 \\
Mejorar economía & 13.3 \\
Empleos mejor pagados & 10.0 \\
Más apoyo al campo & 10.0 \\
Asesoramiento financiero & 10.0 \\
Otras (mejorar la infraestructura, fortalecer el turismo, más & \\
equidad, apoyo al deporte y las artes, apoyo a los discapacitados & 20.0 \\
y consciencia ambiental) & \\
\hline Fuente: elaboración propia. & \\
\hline
\end{tabular}


allegados; a la gente de provincia los tienen marginados. No hay apoyo para industria, para el campo, y eso se estanca, va estancando la economía, hay inseguridad, vagancia, de todo (Gabriel S., entrevistado en Luvianos).

Falta trabajo y que ayude el gobierno, pues que es lo más importante. Sí, de que los salarios mejoren, que haya trabajo, pues. Se va mucha gente a Estados Unidos porque no hay trabajos aquí (Raymundo A., entrevistado en Tlatlaya).

\section{Comentarios finales}

La experiencia laboral, edad y escolaridad son factores que condicionan a los migrantes retornados de la Región Tejupilco, además de diversos compromisos y la responsabilidad familiar que los llevan a buscar empleo en el extranjero, desempeñarse y mantenerse fuera para poder enviar recursos a casa, lo cual implica soportar ritmos de vida distintos, episodios de estrés, soledad, miedo y otras sensaciones. No obstante, los retornados de Tejupilco muestran que estas adversidades fuerzan y motivan la adquisición de conocimientos laborales y habilidades personales que les permiten desempeñarse en otros ambientes. Algunos de los oficios que realizaban en la región también los llevaron a cabo en Estados Unidos, aunque técnicamente fueran distintos. Lo anterior sugiere que los conocimientos que trajeron sólo fueron depuraciones de lo que ya sabían, pero otros sí fueron nuevos, unos de carácter básico y otros de mayor calificación. Además, la mayoría considera que también obtuvo beneficios sociopersonales y económicos con su migración.

$\mathrm{Al}$ retornar a la región, todo viene con los migrantes. Construcción de casas, conocimientos en restaurantes, oficios diversos, formación de patrimonio económico, ahorros, educación de los hijos, madurez emocional, adquisición de hábitos de honestidad, responsabilidad. Sin embargo, en sus localidades, 90\% de ellos no ha encontrado la forma de aplicar en forma productiva sus conocimientos laborales y productivos. Esta es una de las críticas recurrentes que hacen los estudios sobre los migrantes que retornan. Los entornos deben ser reacondicionados para permitir a los migrantes aplicar sus conocimientos y capacidades productivas, así como ahorros e intenciones de emprendimiento para que ellos mismos puedan construir modos de vida más estables.

En la Región Tejupilco un tercio de los migrantes no ha podido aplicar nada, 10\% vive de sus conocimientos, los demás los aplican poco en forma irregular y se ayudan, pero en promedio $90 \%$ mantiene sus conocimientos ociosos. En cambio, ejercen lo que saben en sus negocios, en su casa, en tareas sociales en la comunidad y reuniones familiares. Señalan diversas restricciones en la región, las cuales podrían verse relajadas con la intervención del gobierno estatal mediante políticas públicas microdirigidas a las necesidades y saberes de los migrantes, a sus capacidades de inversión y participación social. Los migrantes reclaman empleos adecuados, mejores salarios, reducción de la violencia, mayor compromiso del gobierno para facilitar apoyos a los proyectos productivos y sociales que desean promover. De otro modo, los jóvenes seguirán trasladándose a Estados Unidos y cada vez en peores condiciones de inseguridad, o en gastos que rondan los 5000 dólares, cantidad que podría servir para instalar un pequeño proyecto con apoyo estatal complementario. Como señalan algunos expertos (Zoltan y Storey, 2004; Gries y Naude, 2011), fomentar el emprendimiento empresarial es positivo para generar cambios estructurales y puede ayudar a formar actores emprendedores responsables de su desarrollo. La curva de aprendizaje empresarial es difícil: quienes buscan emprender proyectos lo hacen porque no ven otras opciones y su espíritu podría flaquear a mediano plazo. Sin embargo, otros, aun teniendo opciones, han decidido abrir sus propios negocios; también podrían aprovechar los tiempos de aprendizaje y fracasos para consolidarse y quizás formar una orientación productiva regional. Dado que la población tiende a emular los logros ajenos, los resultados de los emprendedores generarían arrastre en otros actores.

\section{Análisis prospectivo}

Esta investigación se realizó con base en un pequeño grupo de migrantes retornados a una región agrícola en el sur de la entidad mexiquense. La selección siguió el procedimiento de bola de nieve, redes de amistades y parentesco. No obstante, estos retornados reflejan con claridad un fenómeno de desaprovechamiento de capacidades productivas y financieras que se puede advertir en otros países, entidades, regiones y localidades. Exhiben también el patrón de reinserción que ocurre en otras partes del país y del mundo: traen consigo conocimientos, actitudes personales, ahorros, ideas aprendidas y depuradas en sus vivencias migrantes. Sin embargo, en sus localidades, la mayoría no encuentra canales adecuados para aplicar productivamente dichas capacidades. Por esta razón se propone que en los entornos donde se detectan migrantes retornados, los gobiernos estatales y otras figuras institucionales deban intervenir para inducir cambios estructurales y generar oportunidades socioproductivas que permitan a los migrantes aplicar sus conocimientos, ideas de negocios y capacidades productivas que les 
permitan construir mejores modos de vida. Es probable que sean incluso ellos mismos, quienes generen oportunidades para más población, que de otro modo seguirá migrando al extranjero. Para las preguntas ¿qué medidas aplicar? o ¿qué apoyos otorgar?, una primera recomendación es considerar la voz del actor. ¿Quién más que el propio retornado sabe las condiciones en que se encuentra, los conocimientos que porta y las ideas de emprendimiento que puede desarrollar? Como se refirió, los migrantes retornados poseen sus propias ideas de qué hacer con lo que saben, lo que necesitan y hasta la forma de implementar sus ideas. Sólo basta preguntarles.
Ausubel, D. (1976): Psicología educativa: un punto de vista cognoscitivo. México: Trillas.

Athukorala, P. (1990). International contract and the reintegration of return migrants: The experience of Sri Lanka, International Migration Review, 24(2). Special issue: Labor recruiting organizations in the developing world (summer).

Banco Mundial (2001). Informe sobre el desarrollo mundial 2000/2001. Lucha contra la pobreza. Washington: Banco Mundial/ Mundi-prensa.

Borodak, D. y M. Piracha, (2010). Occupational choice of return migrants in Moldova, Discussion paper, 5207.

Carretero, R. (2012). La comunidad trashumante y hospitalaria como identidad narrativa, Zamora. Michoacán. Colegio de Michoacán, Fideicomiso "Felipe Teixidor y Monserrat de Teixidor".

Chambers, R. y Conway, G. (1992). Sustainable rural liveliboods: Practical concepts for the 21st Century. Brighton: University of Sussex.

Chávez, A. (1995). Migración de retorno y modernización. Debate Agrario. Análisis $y$ alternativas, 21, 21-83.

Dustmann, C. (2001). Return migration, wage differentials, and the optimal migration duration. Canterbur: Instituto para el Estudio del Trabajo (IZA)-Depar- tamento de Economía-Universidad de Kent.

Espinosa, V. (1998). El dilema del retorno. Migración género y pertenencia en un contexto trasnacional. Zamora: El Colegio de Michoacán/El Colegio de Jalisco.

Gries, T. y Naude, W. (2011). Entrepreneurship and human development: A capability approach. Journal of Public Economics, 95, 216-224.

Lucas, R. y Stark, O. (1985). Motivations to remit: evidence from Botswana. Journal of Political Economy, 93, 901-918.

Monereo, C., Castello, M., Clariana, M., Palma, M. y Pérez, M. L. (1999). Estrategiasy enseñanzas de aprendizaje. Barcelona: Gaó.

Papail, J. (2003). Migraciones internacionales y familias en áreas urbanas del centro occidente de México. Papeles de Población, 9(36), 109-131.

Piaget, J. (1978). La equilibración de las estructuras cognitivas. Madrid: Siglo XxI.

Piracha, M. y Vadean, F. (2009). Return migration and occupational choice. Canterbur: Instituto para el Estudio del Trabajo (IZA)-Departamento de Economía-Universidad de Kent.

Reyes, R. y Gijón, S. (2007). Desarrollo rural, migración internacional y escasez de mercados financieros en México. Trace, 52, 45-62.
Sabatés, R. (2007). Desarrollo y utilización de habilidades: el caso de los migrantes en León, Guanajuato, procedentes de la Ciudad de México. Estudios Demográficos y Urbanos, 22, 79-99.

Salas, R. (2010). Migración internacional, migrantes de retorno, remesas y actividades productivas en San Miguel Coatlán, Oaxaca. Reporte de investigación. Toluca: Universidad Autónoma del Estado de México.

Salas, R. (2011). Las aportaciones técnicas y humanas que realizan los migrantes internacionales de retorno en el Estado de México. Cofactor. Revista del Consejo de Investigación y Evaluación de la Política Social, 2(4), 106-136.

Stark, O. (1982). Research on rural to urban migration in LDCs: the confusion frontier and why we should pause to rethink afresh. World development, 10(1).

Thomas Hope, E. (1999). Return migration to Jamaica and its development potential. International Migration, 37(1), 183-205.

Women's Refugee Commission (2009). Building livelihoods. A field manual for practitioners in bumanitarian settings. New York: Women's Refugee Commission.

Zoltan, A. y Storey, D. (2004). Introduction: entrepreneurship and economic development. Regional Studies, 38(8), 871-877. 